\title{
Condylar position changes after three months of treatment with posterior bite turbo
}

\author{
Cambios de posición condilar después de tres meses de tratamiento con \\ tope de mordida posterior
}

\author{
Santiago Herrera Guardiolaㄹ, Germán Eduardo Puerta Salazar², Carlos Humberto Martínez Cajas ${ }^{3}$
}

DDS. Specialist in Orthodontics. Private practice, Universidad del Valle. Cali, Colombia. ORCID: 0000-0002-0877-6909

DDS. Professor, Specialist in Orthodontics. Universidad del Valle. Cali, Colombia. ORCID: 0000-0003-4182-480X

DDS. MSc in Epidemiology, UNICOC. Cali, Colombia. ORCID: 0000-0002-4392-8453

\begin{abstract}
Introduction: all orthodontic treatments must be safe in terms of temporomandibular joint health. No reports in the recent literature evaluate the association between the use of posterior bite turbos and condylar position changes. The aim of the present study was to evaluate condylar position changes occurring after three-month treatment with posterior bite turbo in patients from the Dental School of the Universidad del Valle. Methods: a sample of 15 hyperdivergent patients was randomly distributed into two groups: Bite Turbo and Control Group. Cone-Beam Computed Tomography (CB-CT) was used to assess the condyle position before the bite turbos bonding to first and second molars, and after three months of use of the appliances. Distances were

Key words: orthodontic appliance, cone-beam computed tomography, temporomandibular joint condyle, dental occlusion taken from the CB-CT by a single operator, and the calibration was tested with intraclass correlation (>0.9). Results: no statistical difference between the position of left and right condyles was detected. However, there was a significant difference in the upper space of the left condyle between the initial and final measurement. Patients reported satisfactory use of the occlusal bite turbo (85.8\%) in three months of treatment. Conclusion: contrary to the expected, the simultaneous use of posterior occlusal appliances with balanced mandibular movements for 3 months did not cause significant changes in condylar position. The patients tolerate well the use of occlusal stops.
\end{abstract}

\section{RESUMEN}

Introducci n: todos los tratamientos de ortodoncia deben ser seguros con respecto a la salud de las articulaciones temporomandibulares. La literatura reciente no reporta estudios en los que se eval e la asociaci n entre el uso de topes de mordida posterior y cambios de posici n condilar. El objetivo del presente estudio consisti en evaluar los cambios de posici n condilar que se produjeron despu $s$ de tres meses de tratamiento con tope de mordida posterior en pacientes de la Facultad de Odontolog a de la Universidad del Valle. $\boldsymbol{M}$ todos: la muestra de 15 pacientes hiperdivergentes se distribuy aleatoriamente en dos grupos: Bite Turbo y Grupo control. Se utiliz tomograf a computarizada de haz de cono para evaluar la posici $n$ del c ndilo antes de la uni $n$ de los topes de mordida a los molares primero y segundo, y despu $s$ de tres meses de uso de los dispositivos. Las distancias fueron tomadas en el tom grafo por un solo operador, y la calibraci $n$ se prob con correlaci $n$ intraclase (> 0.9). Resultados: no se detect ninguna diferencia estad stica entre la posici n de los c ndilos izquierdo y derecho. Sin embargo, hubo una diferencia significativa en el espacio superior del c ndilo izquierdo entre la medici n inicial y final. Los pacientes notificaron un uso satisfactorio del bite turbo oclusal $(85,8 \%)$ despu s de tres meses de tratamiento. Conclusi $n$ : contrario a lo que se supon a, el uso simult neo de aparatos oclusales posteriores con movimientos mandibulares equilibrados durante 3 meses no caus cambios significativos en la posici $n$ de los c ndilos. Los pacientes toleran bien el uso de topes oclusales.

\author{
Palabras clave: \\ aparato de orto- \\ doncia, tomograf a \\ c ndilc \\ c ndilo articular \\ temporomandibu- \\ lar, oclusi n dental
}

Submitted: June 29/2018 - Accepted: October 29/2019

How to quote this article: Herrera-Guardiola S, Puerta-Salazar GE, Mart nez Cajas CH. Condylar position changes after three months of treatment with posterior bite turbo. Rev Fac Odontol Univ Antioq. 2020; 32(1): 18-25. DOI: http://dx.doi.org/10.17533/udea.rfo.v32n1a2 


\section{INTRODUCTION}

The human temporomandibular joint (TMJ) has been described by many authors ${ }^{1-4}$ as a unique kind of joint because of several reasons: 1 ) the articular surface is covered by fibrocartilage instead of hyaline cartilage. 2) It functions as two independent articulations with coordinated complex movements. 3) There is a notorious difference among the components. 4) Movements are affected by contacts between dental surfaces, and 5) The fibrous cartilage surrounding the mandibular condyle divides the joint into two areas: upper and lower.

The relationship between glenoid fossa and mandibular condyle has been studied by many authors, ${ }^{5-8}$ who consider that the ideal condyle position is one that provides enough muscle relaxation, occlusal stability, and absence of discrepancies with the glenoid fossa. It is considered that condyle discrepancies over $4 \mathrm{~mm}$ may induce temporomandibular disorders. ${ }^{9}$

The use of anterior bite turbos or occlusal stops in molar teeth is a common practice in current orthodontic treatments, ${ }^{10}$ when enhancing vertical dimension is necessary to release the occlusion during orthodontic movement, thus reducing treatment time. ${ }^{11-14}$

There is evidence ${ }^{9,15}$ that occlusal interferences are not the actual factors inducing temporomandibular disorders, but they play a secondary role in their multifactorial development. ${ }^{9}$ Only increased overjet is considered as an occlusal risk factor for articular disfunction. ${ }^{16,17}$ while systemic factors such as stress and emotional status are more relevant risk factors. ${ }^{12,13,18}$

The aim of this study was to evaluate condylar position changes related to the use of Bite Turbo fixed appliances in adult patients' molar region during three months of treatment, compared with healthy orthodontic patients, using Cone-Beam Computed Tomography (CB-CT).

\section{METHODS}

The project was designed as a case-control study. After standard clinical diagnostic exam of TMD, the patients were informed about the study benefits, risks, and treatment alternatives, and they were asked to sign an informed consent.

The inclusion criteria were patients up to 18 years of age who had completed their skeletal growth. The patients must have dolichofacial biotype, positive overjet or edge to edge relationship, positive overbite or anterior open bite, and Class I and II molar relationship. The exclusion criteria were patients with temporomandibular joint disorders (TMJD), with no previous TMJ or maxillofacial surgery, no muscle or TMJ pain, deep bite and anterior crossbite. Pregnant patients were also excluded.

The study started with 34 patients, but 19 were excluded per the exclusion criteria: 10 had an initial TMJD, 8 refused to participate, and 1 did not show up for the second tomography. Therefore, the study was completed with 15 patients: 7 in the experimental group and 8 in the control group. The whole sample included 9 women $(60 \%)$ and 6 men $(40 \%)$. The average age of participants was $25.93 \pm 8.54$ years.

Two tomographic images were obtained for each patient. 6 spaces ( 3 for each side) were measured in $\mathrm{mm}$ in each image. Each patient was identified with a fourdigit code: two in order of arrival and two according to gender (01 female, 02 male). 
They were randomly allocated to either the experimental or the control group, and the first tomographic register was taken $\left(T_{1}\right)$. The second tomography was obtained three months after the insertion of appliances $\left(T_{2}\right)$. In addition, a satisfaction test was applied to the patients.

The TMJ measurements were obtained using CB-CT (I-CAT 17-19 [Imaging Sciences International], model 1-10-1-0 serial ICU080600). The subjects were placed in standing position, with their heads in natural position. The software (I-CAT Vision Q, Brea, CA - USA) was used to obtain images of the sagittal section of the condylar head by bisecting the long axis of the condyle in the vertical plane. The true horizontal line was used as reference to obtain the linear measurements of the articular space, taking the uppermost point of the auditory meatus and the upper point of the glenoid fossa. The upper joint space was the distance between the most superior condyle point to the most superior aspect of the glenoid fossa. Lines tangent to the most prominent anterior and posterior contacts of the condyle were drawn from the superior aspect of the glenoid fossa. Perpendicular distances from the anterior and posterior tangents points of the condyle to the anterior and posterior points of the fossa were measured (Figure 1). ${ }^{19}$

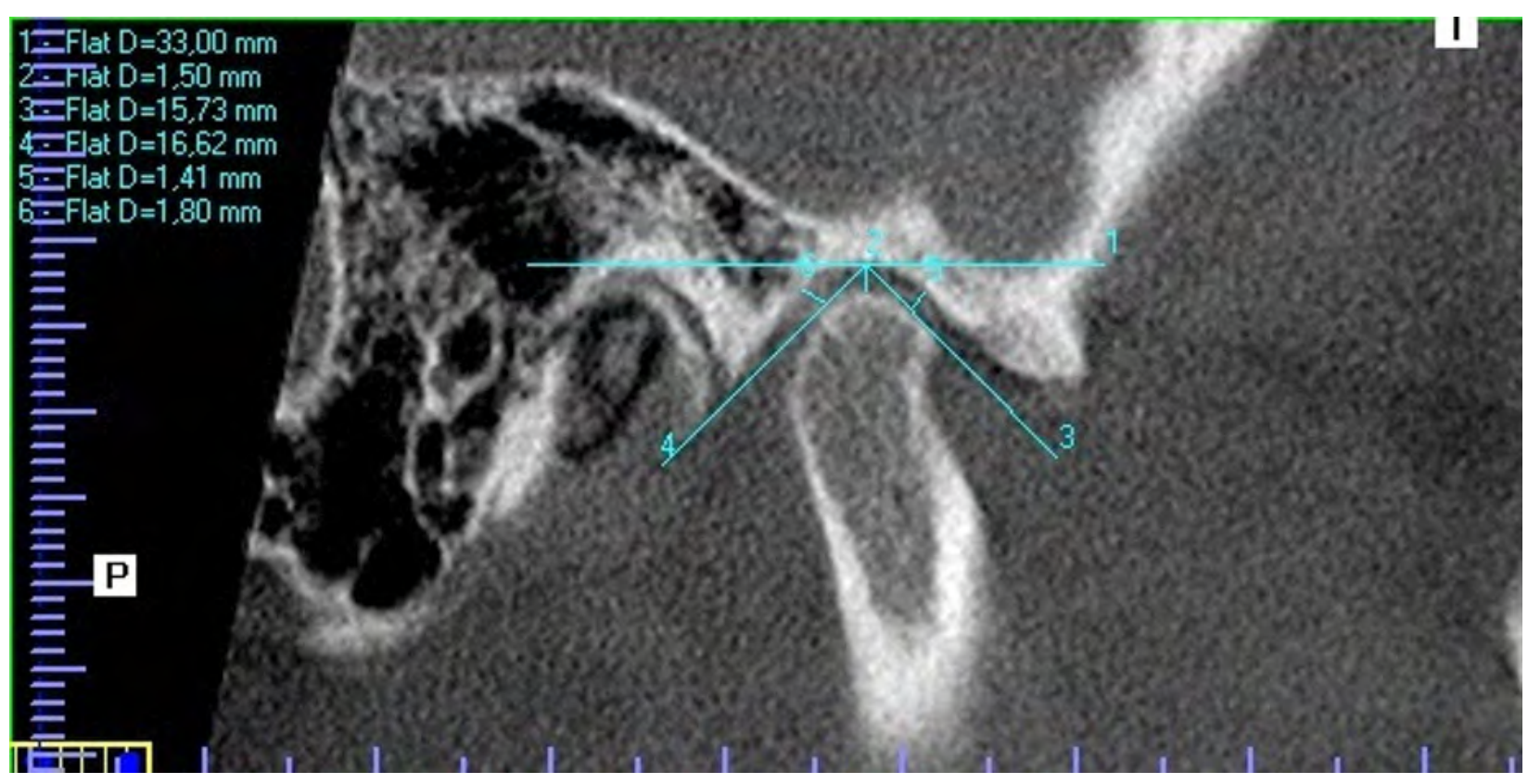

Figure 1. A patient's CBCT. The true horizontal line was taken as a reference to establish condyle position in the glenoid fossa. 2 is the upper articular space, 5 is the anterior articular space, 6 is the posterior articular space

Source: by the authors

Bite turbos (occlusal stops) made from prefabricated minimolds (minimolds ${ }^{\circledR}$, Ortho Technology ${ }^{\circledR}$, USA) of lower permanent first and second molar teeth were used in the experimental group. The protocol to adhere bite turbos included hydrogen peroxide 
prophylaxis, $37 \%$ orthophosphoric acid demineralization for 20 seconds, rinsing for 20 seconds, drying with triple syringe, adhesive application, polymerization for 20 seconds, resin filling of the prefabricated mold and polymerization, lifting the posterior occlusion by $2 \mathrm{~mm}$.

The protocol was approved by the Ethics Committee and classified as an over-theminimal risk study.

The statistical analysis included tests for operator's calibration (intraclass correlation $>0.9$ ), Mann-Whitney and Wilcoxon tests for group comparison and $T_{1}$ vs $T_{2}$ comparison of measurements.

\section{RESULTS}

The results in both groups (control and bite turbo) yielded no significant differences in all the articular measurements in $\mathrm{T}_{1}$ (anterior, upper, and posterior articular spaces). These results explain the similar distribution in both samples (figure 2).

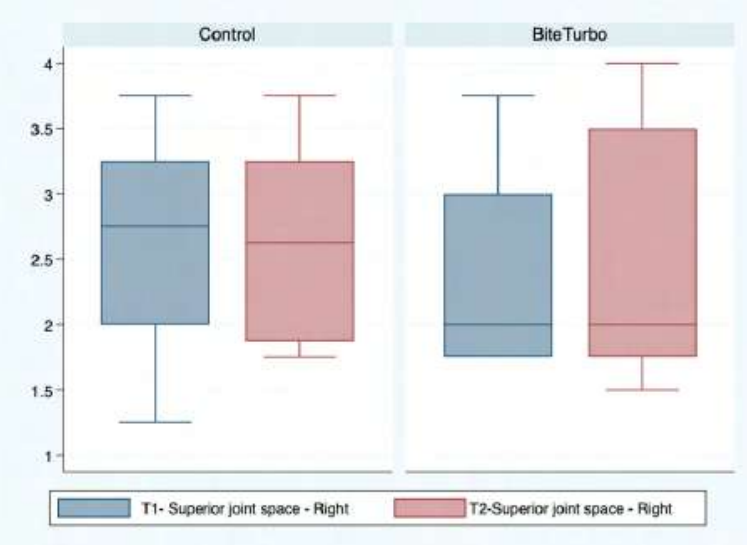

Figure 2. Box plot for the right upper articular space at $T_{1}$ and $T_{2}$ in both groups

Source: by the authors
The control group did not show significant differences between $T_{1}$ and $T_{2}$ in any of the variables measured (Table 1 ).

Table 1. Results per group. Comparison of time changes between $\mathrm{T} 1$ and $\mathrm{T} 2$ by Wilcoxon test

\begin{tabular}{|c|c|c|c|}
\hline & \multicolumn{3}{|c|}{ Control Group } \\
\hline & $\mathrm{T}_{1}$ & $\mathrm{~T}_{2}$ & $P$ value \\
\hline & Average \pm SD & Average \pm SD & $>|z|$ \\
\hline Right anterior space & $1.89 \pm 0.59$ & $2.04 \pm 0.47$ & 0.21 \\
\hline Left anterior space & $2.21 \pm 0.79$ & $2.06 \pm 0.67$ & 0.33 \\
\hline Right upper space & $2.69 \pm 0.83$ & $2.63 \pm 0.78$ & 0.88 \\
\hline Left upper space & $2.81 \pm 0.70$ & $2.84 \pm 0.60$ & 0.94 \\
\hline Right posterior space & $2.32 \pm 0.87$ & $2.09 \pm 0.69$ & 0.57 \\
\hline \multirow[t]{3}{*}{ Left posterior space } & $2.09 \pm 1.05$ & $2.03 \pm 0.48$ & 0.73 \\
\hline & \multicolumn{3}{|c|}{ Bite Turbo Group } \\
\hline & $\mathrm{T}_{1}$ & $\mathrm{~T}_{2}$ & $\begin{array}{c}P \text { value } \\
>|z|\end{array}$ \\
\hline Right anterior space & $2.00 \pm 0.50$ & $2.21 \pm 0.80$ & 0.26 \\
\hline Left anterior space & $1.70 \pm 0.66$ & $1.95 \pm 0.60$ & 0.15 \\
\hline Right upper space & $2.29 \pm 0.78$ & $2.43 \pm 0.94$ & 0.26 \\
\hline Left upper space & $1.75 \pm 0.25$ & $1.54 \pm 0.22$ & $0.03^{*}$ \\
\hline Right posterior space & $2.08 \pm 0.59$ & $2.21 \pm 0.62$ & 0.67 \\
\hline Left posterior space & $1.75 \pm 0.19$ & $1.81 \pm 0.27$ & 0.26 \\
\hline
\end{tabular}

Source: by the authors

On the other hand, the difference between $\mathrm{T}_{1}$ and $\mathrm{T}_{2}$ in the bite turbo group was not significant, except for a significant change in dimensions of left upper articular space $(p=0.0283)$ (Table 1).

The left upper articular space had significant differences when a comparison was made between both groups (Mann-Whitney test: $p=0.004$ probability). They had a difference of $1.00 \mathrm{~mm}$ with the Wilcoxon pair test (Figure 3). 


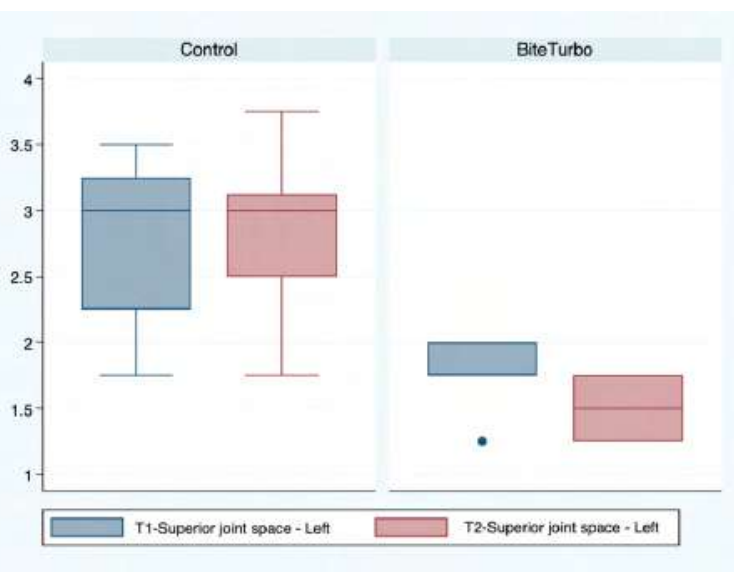

Figure 3. Box plot for the left upper articular space at $T_{1}$ and $\mathrm{T}_{2}$ for both groups

Source: by the authors

Patients using bite turbo reported the experience as completely satisfactory in $42.9 \%(n=3)$ and satisfactory in $42.9 \%(n=3)$, while $14.3 \%(n=1)$ considered the use of bite turbo as indifferent. The most relevant negative outcome reported by patients was masticatory difficulty, reported by $42.9 \%$ of them. However, $85.7 \%$ reported that if necessary, they would use the appliances again (Table 2).

Table 2. Level of satisfaction with the use of bite turbo

\begin{tabular}{ccr}
\hline & \multicolumn{2}{c}{ Bite turbo group } \\
\cline { 2 - 3 } & & $\%$ \\
\hline \multirow{2}{*}{ Esthetic Compromise } & No & 100.0 \\
Use bite turbo again & Yes & 0.0 \\
Oral hygiene difficulty & No & 14.3 \\
& Yes & 85.7 \\
Communication difficulty & No & 100.0 \\
& Yes & 0.0 \\
Masticatory difficulty & No & 85.7 \\
& Yes & 14.3 \\
Satisfaction score & No & 57.1 \\
& Yes & 42.9 \\
& Completely Unsatisfactory & 0.0 \\
& Unsatisfied & 0.0 \\
& Indifferent & 14.3 \\
\hline
\end{tabular}

Source: by the authors

\section{DISCUSSION}

The use of CBCT to obtain reliable measurements of condylar changes in the mid-term (3 months) is a great advantage of the present study. But there are two obvious limitations in the study: a small number of patients and the short follow up period. Due to the small number of participants per group, it was necessary to apply nonparametric tests (Wilcoxon, Mann-Whitney) to analyze the results. The only significant change in condylar position was the vertical position of the left condyle, which after three months of bite turbo use was $0.22 \mathrm{~mm}$ higher.

The participants had a dolichofacial skeletal biotype, which is the most susceptible to condylar horizontal and vertical changes. ${ }^{20}$ Therefore, it can be suggested that hypodivergent patients, due to their adequate muscular and ligamentous stability, do not tend to present changes in condylar position with the use of bite opening occlusal appliances, ${ }^{20}$ but it is necessary to complete the study in larger samples that include other facial biotypes.

In hyperdivergent patients, it has been reported a condylar deflection that tends to place the TMJ ligament in a more stable occlusal position. ${ }^{9}$ In the present group of patients there was no molar fulcrum, as the appliances were prepared and adjusted to obtain simultaneous contacts of the same intensity in first and second molars in order to achieve better occlusal stability. Therefore, considering the mid-term results obtained, it is possible to conclude that no significant deleterious changes in the condyle will occur.

During the masticatory activity, the mandibular dynamics shows mandibular 
rotation in the sagittal plane, as reported by in-vitro studies. This bending is probably generated by vertical components of muscular force and by the condylar reaction to the biting force. The magnitude of sagittal mandibular rotation depends on the site and magnitude of the force applied to generate the fulcrum. But the masticatory dynamics is different as the pattern of rotation incorporates a balance side and a working side, producing torsion and transversal rotation. $^{21}$

In the cases treated with bite stops there was no de-cementation of the appliance. Therefore, during the masticatory function there was apparently a balance between the balance side and the working side, as all the patients reported balanced masticatory activity.

Various studies report the incidence of temporomandibular disorders in hyperdivergent patients, and that tendency might be in part responsible for the absence of those cases in the present groups, which excluded patients with TMJ symptoms or under treatment. This differs from the study by Nebbe and Major, which included mostly female patients with TMJD. ${ }^{22}$ During the present study, a bite turbo patient presented articular noises and discomfort in the articular zone, but when the appliances were removed the patient returned to the initial healthy situation.

In another pilot study conducted at the Universidad del Valle ${ }^{1}$, condylar changes after use of bite turbos in the palatal side of upper incisors for six weeks were not significant either. The present study differs from that pilot study because of the significant vertical change observed in the left side after a longer follow up period.

1 Graduate thesis by Dr. Germán Eduardo Puerta Salazar. Unpublished.
The lack of significant changes in condylar position in the present study may be explained by the location of the stops in first and second molars, with simultaneous contacts during mouth close and freedom for eccentric movements. Biomechanically, the stops were located before the line of action of elevator muscles, a situation that does not affect the fulcrum during mandibular closure.

This study did not evaluate the transversal conditions that could possibly affect the temporomandibular joint, as the main objective was to evaluate the sagittal plane; nevertheless, further studies are recommended to evaluate the possible changes on the coronal plane of the TMJ.

We suggest further research in this field, verifying if the vertical differences in the left TMJ could be clinically relevant in a longer period of time.

\section{CONCLUSIONS}

Contrary to what was expected, the simultaneous use of posterior occlusal appliances with balanced mandibular movements for 3 months did not induce significant changes in condylar position. The occlusal stops in first and second molar teeth are located before the masseter and medial pterygoid muscles, so the mandible mechanic behavior should not change, as it is not altering condylar position. The patients tolerated well the use of occlusal stops.

\section{CONFLICTS OF INTEREST}

The authors declare that they have no conflicts of interest. 


\section{CORRESPONDING AUTHOR}

Santiago Herrera Guardiola

Facultad de Odontolog a, Universidad del

Valle
(+57) 3164038297

santiago.ortodonciaestetica@gmail.com

Calle 20N \# 4N-45 Consultorio 301

Cali, Colombia

\section{REFERENCES}

1. Friedman $\mathrm{MH}$, Weisber J. Application of orthopedic principles in evaluation of the temporomandibular joint. Phys Ther. 1982; 62(5): 597-603. DOI: https://doi.org/10.1093/ptj/62.5.597

2. Hidaka O, Adashi S, Takada K. The difference in condylar position between centric relation and centric occlusion in pretreatment Japanese orthodontic patients. Angle Orthod. 2002; 72(4): 295-301. DOI: https://doi.org/10.1043/0003-3219(2002)072\%3C0295:TDICPB\%3E2.0.CO;2

3. Posselt U. Physiology of occlusion and rehabilitation. Oxford, England: Blackwell Scientific Publications; 1969.

4. Wang L, Lazebnik M, Detamore MS. Hyaline cartilage cells outperform mandibular condylar cartilage cells in a TMJ fibrocartilage tissue engineering application. Osteoarthr Cartil. 2009; 17(3): 346 - 53. DOI: https://doi.org/10.1016/j.joca.2008.07.004

5. Tsuruta A, Yamada K, Hanada K, Hosogai A, Kohno S, Koyama J et al. The relationship between morphological changes of the condyle and condylar position in the glenoid fossa. J Orofac Pain. 2004; 18(2):148-55.

6. Watted N, Witt E, Kenn W. The temporomandibular joint and the disc-condyle relationship after functional orthopaedic treatment: a magnetic resonance imaging study. Eur J Orthod. 2001; 23(6): 683-93. DOI: https://doi.org/10.1093/ejo/23.6.683

7. Mejia CA, Salazar L. Desarrollo ontog nico de la articulaci $n$ temporo-mandibular durante el periodo fetal. Revista Estomatol gica. 1996; 6:1-72.

8. Rinchuse DJ, Kandasamy S. Articulators in orthodontics: an evidence-based perspective. Am J Orthod Dentofacial Orthop. 2006; 129(2): 299-308. DOI: https://doi.org/10.1016/j.ajodo.2005.03.019

9. McNamara J, Seligman D, Okeson J. Occlusion, orthodontic treatment and temporomandibular disorders: a review. J Orofac Pain. 1995; 9(1): 73-90.

10. Kozlowski J. Honing Damon System Mechanics for the Ultimate in Efficiency and Excellence. Clin Impressions. 2008; 16: 23-8.

11. Iscan HN, Sarisoy L. Comparison of the effects of passive posterior bite-blocks with different construction bites on the craniofacial and dentoalveolar structures. Am J Orthod Dentofacial Orthop. 1997; 112(2): 171-8. DOI: https://doi.org/10.1016/s0889-5406(97)70243-9

12. Michelotti A, lodice G. The role of orthodontics in temporomandibular disorders. Journal Oral Rehabil. 2010; 37(6): 411-29. DOI: https://doi.org/10.1111/j.1365-2842.2010.02087.x

13. Conti A, Freitas M, Conti P, Henriques J, Janson G. Relationship between signs and symptoms of temporomandibular disorders and orthodontic treatment: a cross-sectional study. Angle Orthod. 2003; 73(4): 411-7. DOI: https://doi.org/10.1043/0003-3219(2003)073\%3C0411:RBSASO\%3E2.0.CO;2 
14. Karl P, Foley T. The use of a deprogramming appliance to obtain centric relation records. Angle Orthod. 1999; 69(2): 117-25. DOI: https://doi.org/10.1043/0003-3219(1999)069\%3C0117:TUOADA\%3E2.3. $\mathrm{CO} ; 2$

15. Rinchuse D, Kandasamy S. Myths of orthodontic gnathology. Am J Orthod Dentofacial Orthop. 2009; 136: 322-30.

16. Tamaki K, Ikeda T, Wake H, Toyoda M. An assessment of condylar dynamics associated with grinding movements. Part 1: Pattern analysis of condylar dynamics. Prosthodont Res Pract. 2007; 6:28-33.

17. Gidarakou IK, Tallents RH, Kyrkanides S, Stein S, Moss ME. Comparison of skeletal and dental morphology in asymptomatic volunteers and symptomatic patients with normal temporomandibular joints. Angle Orthod. 2003; 73(2): 116-20. DOI: https://doi.org/10.1043/0003-3219(2003)73\%3C116:COSADM\%3 E2.0.CO;2

18. Pahkala R, Qvarnstrom M. Can Temporomandibular dysfunction signs be predicted by early morphological or functional variables? Eur J Orthod. 2004; 26: 367-73.

19. Ikeda K, Kawamura A. Assessment of optimal condylar position with limited cone-beam computed tomography. Am J Orthod Dentofacial Orthop. 2009; 135(4): 495-501. DOI: https://doi.org/10.1016/j. ajodo.2007.05.021

20. Girardot RA. Comparison of condylar position in hyperdivergent and hypodivergent facial skeletal types. Angle Orthod. 2001; 71(4): 240-46. DOI: https://doi.org/10.1043/0003-3219(2001)071\%3C0240:COC $\mathrm{PIH} \% 3 \mathrm{E} 2.0 . \mathrm{CO} ; 2$

21. van Eijden TM. Biomechanics of the mandible. Crit Rev Oral Biol Med. 2000; 11(1): 123-36. DOI: https:// doi.org/10.1177/10454411000110010101

22. Nebbe B, Major PW. Prevalence of TMJ disc displacement in a pre-orthodontic adolescent sample. Angle Orthod. 2000; 70(6): 454-63. DOI: https://doi.org/10.1043/0003-3219(2000)070\%3C0454:POTDDI\%3 E2.0.CO;2 